\title{
Birth-related subconjunctival and retinal haemorrhages in the Newborn Eye Screening Test (NEST) Cohort
}

\author{
Marco H. Ji ${ }^{1}$ Cassie A. Ludwig ${ }^{1} \cdot$ Natalia F. Callaway $\mathbb{D}^{1} \cdot$ Darius M. Moshfeghi $\mathbb{( I D}^{1}$
}

Received: 17 June 2019 / Accepted: 25 June 2019 / Published online: 8 July 2019

(c) The Royal College of Ophthalmologists 2019

Birth trauma is a putative cause of newborn retinal haemorrhages [1] and subconjunctival haemorrhages [2]. However, in the Newborn Eye Screen Testing (NEST) study, we found no correlation between these two types of haemorrhages. The NEST study was a prospective cohort study conducted at Lucile Packard Children's Hospital at Stanford University School of Medicine that aims to identify the birth prevalence of ocular diseases. The study was conducted in accordance with the Health Insurance Portability and Accountability Act (HIPAA) and the tenets of the Declaration of Helsinki and with local approval of the Institutional Board Review (IRB 25098). In this cohort, 41/ $234(17.5 \%)$ infants showed some form of retinal haemorrhages, but only 21/234 (9\%) showed subconjunctival haemorrhages and among them, only 5 presented with concomitant retinal haemorrhage and no correlation was found between these two forms of haemorrhages (Risk Ratio 95\% Confidence Interval, 0.312, 1.613). The group with subconjunctival haemorrhages was born with higher birth weight (BW) compared to those without subconjunctival haemorrhages (mean difference $287.6 \mathrm{~g}, \quad p=0.008$ ), whereas babies with retinal haemorrhages did not differ from those without retinal haemorrhages in terms of $\mathrm{BW}(p=$ 0.759). Furthermore, the risk for subconjunctival haemorrhages was not increased by a history of instrumental delivery as it was for retinal haemorrhages. Even though in the literature both of them have been linked to birth trauma, subconjunctival haemorrhages are more likely caused by a chest compression during the passage through the birth canal with a sudden increase of venous pressure in the head and neck $[2,3]$. A higher BW that results in a larger chest might

Darius M. Moshfeghi

dariusm@stanford.edu

1 Horngren Family Vitreoretinal Center, Department of Ophthalmology, Byers Eye Institute, Stanford University School of Medicine, Palo Alto, CA 94305, USA increase this risk further. In contrast, retinal haemorrhages at birth are usually due to compression of the eyeball and especially with vacuum or forceps [1]. Recently Dr. Moshfeghi proposed that neonatal retinal haemorrhages may fall into the spectrum of Terson syndrome, or the association between retinal and intracranial haemorrhages caused by a sudden increase in intracranial pressure [4]. Even though both phenomena are strictly associated with birth trauma, subconjunctival and retinal hemorrhages may not share a common pathophysiology.

Funding This work was funded by the Heed Ophthalmic Foundation awarded to NFC.

\section{Compliance with ethical standards}

Conflict of interest DM has the following disclosures: Consultant: Akebia, Congruence, SAB: Allergan; Allegro, Clearside, Equity: dSentz, Grand Legend Technologies, Promisight, Versl, Visunex; Steering Committee/Data Monitoring Committee: Bayer Genentech, Regeneron, Novartis, Iconic Therapeutics. Board of Director:1800 Contacts, dSentz, Promisight, Versl, Linc, Pr3vent. The remaining authors declare that they have no conflict of interest.

Publisher's note: Springer Nature remains neutral with regard to jurisdictional claims in published maps and institutional affiliations.

\section{References}

1. Callaway NF, Ludwig CA, Blumenkranz MS, et al. Retinal and optic nerve hemorrhages in the newborn infant: one-year results of the newborn eye screen test study. Ophthalmology. 2016;123:1043-52.

2. Katzman GH. Pathophysiology of neonatal subconjunctival hemorrhage. Clin Pedia. 1992;31:149-52.

3. Spitzer SG, Luorno J, Noël LP. Isolated subconjunctival hemorrhages in nonaccidental trauma. J AAPOS. 2005;9:53-6.

4. Moshfeghi DM. Terson syndrome in a healthy term infant: delivery-associated retinopathy and intracranial hemorrhage. Ophthalmic Surg Lasers Imaging Retin. 2018;49:e154-6. 